\title{
Las Caletas de Chile: I ntegración urbana y prevalencia de sus valores patrimoniales. EI caso de la bahía de Coquimbo.
}

Coves of Chile: Urban integration and the prevalence of their heritage values. The case of Coquimbo bay

Alejandro Orellana Mc Bride, María Macarena Díaz

\section{Filiación}

Universidad de La Serena

E mail: aorellana@userena.cl, mmdiaz@userena.cl

Primera versión recibida en: 19 de abril, 2016 Última versión recibida en: 26 de junio, 2016

\section{Resumen}

Las caletas en Chile se remontan a tiempos prehispánicos y que presentan un modo de vida asociado a una economía familiar heredada por generaciones. Algunos de estos asentamientos sostienen relaciones de dependencia y conflicto con núcleos urbanos mayores. Tal es el caso de la bahía de Coquimbo, donde San Pedro y Peñuelas constituyen pequeños poblados en proceso de integración dentro del sistema conurbano de La Serena-Coquimbo. Por medio de un análisis socioespacial se indaga en el grado de integración de estas localidades en el sistema urbano y las relaciones que establecen las comunidades de las caletas con su espacio habitado, identificando los elementos formales y espaciales más valorados y apropiados por sus habitantes, junto con los elementos de identidad comunitaria y su soporte contextual. Queda en evidencia la estrecha relación entre actividad productiva y espacio residencial, factor fundamental en la conservación y desarrollo identitario del borde costero, en un contexto de vulnerabilidad ante amenazas naturales y antrópicas.

\section{Palabras clave}

Caletas urbanas; patrimonio; integración urbana; Coquimbo

\begin{abstract}
Fishing coves in Chile have originated back into even prehistoric times and represent a way of life associated with a family economy passed on from generation to generation. Some of these settlements have a relationship of dependency and conflict with the larger nuclear urban centers. Such is the case of the Coquimbo Bay where San Pedro and Peñuelas, are little settlements in the process of being integrated into the conurbation of La Serena-Coquimbo. Using a socio-spatial analysis, this investigation inquiry into the relationships that the cove communities establish with their inhabited space, identifying the formal and spatial elements that are most valued and appropriated by their inhabitants along with the elements of community identity and their contextual support. It's evident the direct relationship between productive activity and residential space, as a fundamental element in the conservation and identity development of the coast border, in context of vulnerability to natural and human threat.
\end{abstract}

\section{Keywords}

Urban Coves; heritage; urban integration; Coquimbo 


\section{Sumario}

1 Metodología

1.1 El caso de estudio

1.2 Dimensiones socio-espaciales del barrio caleta Peñuelas

1.3 Dimensiones socio-espaciales del barrio caleta San Pedro

2 Grado de integración urbana caletas urbanas

3 Percepción de barrio y valoración del patrimonio

$4 \quad$ Consideraciones finales

Referencias

\section{I ntroducción}

Las caletas de Chile

En el litoral chileno existen 240 caletas pesqueras (Servicio Nacional de Pesca, 2013). El concepto caleta alude a centros productivos de extracción, procesamiento y venta de productos marinos, como pescados, mariscos y algas, que usualmente están asociados a pequeños poblados de carácter rural. Estos asentamientos, también llamados "caletas", constituyen unidades espaciales y socioeconómicas que combinan espacios de trabajo, comunitario y doméstico con un fuerte sentido de identidad, valores y patrimonio cultural (Marcucci, 2014).

Las condiciones geográficas de su emplazamiento presentan aspectos favorables, tanto para el asentamiento humano, como para las actividades productivas. Normalmente, se trata de bahías protegidas con tramos de playas donde existen bancos naturales de recursos marinos y suelen estar situadas en lugares donde existen afluentes de agua dulce o desembocaduras de ríos.

Estas condiciones preexistentes del territorio dieron lugar a la conformación de un sistema de asentamientos de grupos humanos, organizados en comunidades dedicadas a la extracción de recursos marinos. Estas comunidades, con gran capacidad de adaptación, construyeron sus tradiciones a través de una acumulación de innovaciones adaptativas a los cambios ambientales (Saavedra y Macías, 2012). Si bien su origen se remonta a tiempos prehispánicos, en tiempos contemporáneos la supervivencia de estas comunidades ha sido posible gracias al potente capital social y la asistencia estatal.

En las caletas de Chile el sistema de producción funciona basado en la solidaridad, el estado tiene un rol asistencial y establece las áreas de manejo en régimen de co-gestión. Este esquema ha fortalecido la capacidad de organización de las caletas, produciendo cohesión social, un fuerte compromiso de los pescadores y confianza en sus liderazgos (Zúñiga, Ramírez y Valdebenito, 2008; 2010; Kosamu, 2015).

La participación estatal se da a través de diversas reparticiones, siendo las principales la Subsecretaría de Marina del Ministerio de Defensa, que determina las áreas de manejo; y la Subsecretaría de Pesca del Ministerio de Economía, que tiene por misión regular y fomentar las actividades productivas de las caletas. Los pescadores, por su parte, están organizados a 
distintas escalas, tales como confederaciones de nivel nacional, federaciones supra-comunales, y sindicatos y gremios de carácter local.

Las caletas, como unidades territoriales, establecen relaciones diferenciales de dependencia económica y administrativa con núcleos urbanos y, con frecuencia, conflictos culturales y ambientales con ellos. Tal es el caso de la Región de Coquimbo, que según su grado de conectividad e integración con los distintos centros urbanos se pueden distinguir cuatro modos de asentamientos costeros o caletas de pescadores, mariscadores o recolectores artesanales (Fig. 1).

Las caletas de tipo "rurales" se distinguen dentro del territorio por estar en una situación de desconexión geográfica con los principales centros de desarrollo. Estas caletas subsisten en precarias condiciones de habitabilidad y conectividad, con mínimas conexiones a servicios básicos y redes, en algunos casos inexistentes. Se ubican en el sector centro sur de la región, siendo su característica más importante la distancia entre el asentamiento costero y la red vial de la carretera Panamericana. Su actividad productiva se concentra principalmente en la recolección de algas.

En un segundo grupo se distinguen las caletas de tipo "urbano-rural". Éstas poseen una mayor infraestructura de servicios, como agua potable y electricidad, conectividad a redes y cercanía a rutas viales que las acercan al sistema urbano. Se agrupan en dos sectores, uno en el extremo norte de la región y el segundo en el extremo sur. Sus actividades principales son la pesca artesanal y marisqueo.

Por último están las caletas "urbanas", que están integradas o en proceso de integración con las tramas urbanas de las ciudades costeras de territorio. Poseen toda la infraestructura y conectividad de servicios disponibles dentro de una ciudad intermedia del sistema nacional, como es el caso del Gran La Serena (conurbación de La Serena y Coquimbo). Es precisamente esta tipología de caleta en las que se enfoca el presente estudio.

Caletas urbanas, integración y vulnerabilidad

Actualmente estas caletas urbanas se encuentran situadas en zonas de intensa actividad inmobiliaria, fuertemente relacionadas con la actividad turística. Con tipologías caracterizadas por condominios de vivienda en altura, restaurantes y centros nocturnos, estos desarrollos se concentran en altas densidades y traen consigo un nuevo tipo de residente (Inzulza, 2012). Este nuevo contexto de borde costero de la bahía contrasta profundamente con el asentamiento tradicional de las localidades estudiadas.

Con el impulso inmobiliario de los últimos 30 años, y con normativas permisivas en la zona costera, se han construido grandes conjuntos de edificación en altura, en especial en el entorno de la caleta Peñuelas, el cual ha experimentado una evidente transformación, pasando de ser un área semi-rural con vocación agrícola y de balneario local, a un área urbana consolida, generando un polo de desarrollo con características orientadas a los servicios turísticos y residenciales en primera línea de playa. En el caso de San Pedro la integración es menor, pero de igual modo está inserta en un territorio en transformación.

Distintos autores definen este proceso como un tipo de gentrificación, en que nuevos grupos con mayor capacidad de pago llegan a controlar el área, elevando de forma generalizada los precios de renta del suelo, siendo este fenómeno inherente a la estructura y funcionamiento de los mercados de suelo (Sabatini et al, 2010). Otras posturas van más lejos y la definen como una injusticia social en que los efectos negativos de los procesos de gentrificación pueden ser más nocivos que los beneficios que ella produce (López Morales, 2009; Lees et al, 2012). Las principales consecuencias negativas que se pueden producir son el desplazamiento o cambio 
del tejido social de un barrio por el aumento de los precios de arriendo y valores de las propiedades debido a la especulación inmobiliaria, disminución de la vivienda económica o social en el sector, presión sobre áreas urbanas contiguas y/o pérdida de heterogeneidad social dentro de los barrios. La transformación de los barrios, además del cambio en las tipologías de viviendas por otras de mayor costo, también ocurre a nivel de prestaciones de servicios y comercio. Se evidencia en cómo los barrios gentrificados por clases altas generan una demanda de bienes y servicios especializados, gastronomía gourmet y tiendas especializadas boutiques, los cuales remplazan a los servicios originales del barrio (Casgrain y Janoschka, 2013)

Si bien en el área de las caletas estudiadas no se observan evidencias de desplazamiento de antiguos residentes (Segeur, 2015), sí se evidencia una transformación socio-espacial en el entorno de las localidades, con la llegada de residentes de estratos alto y medio-alto que habitan edificios en altura, provocando una tensión espacial entre las nuevas edificaciones y los volúmenes preexistentes de viviendas unifamiliares. La gran escala de los barrios verticales contrasta con las lógicas volumétricas y de ocupación del espacio público de las viviendas unifamiliares en la caleta (Fig. 2).

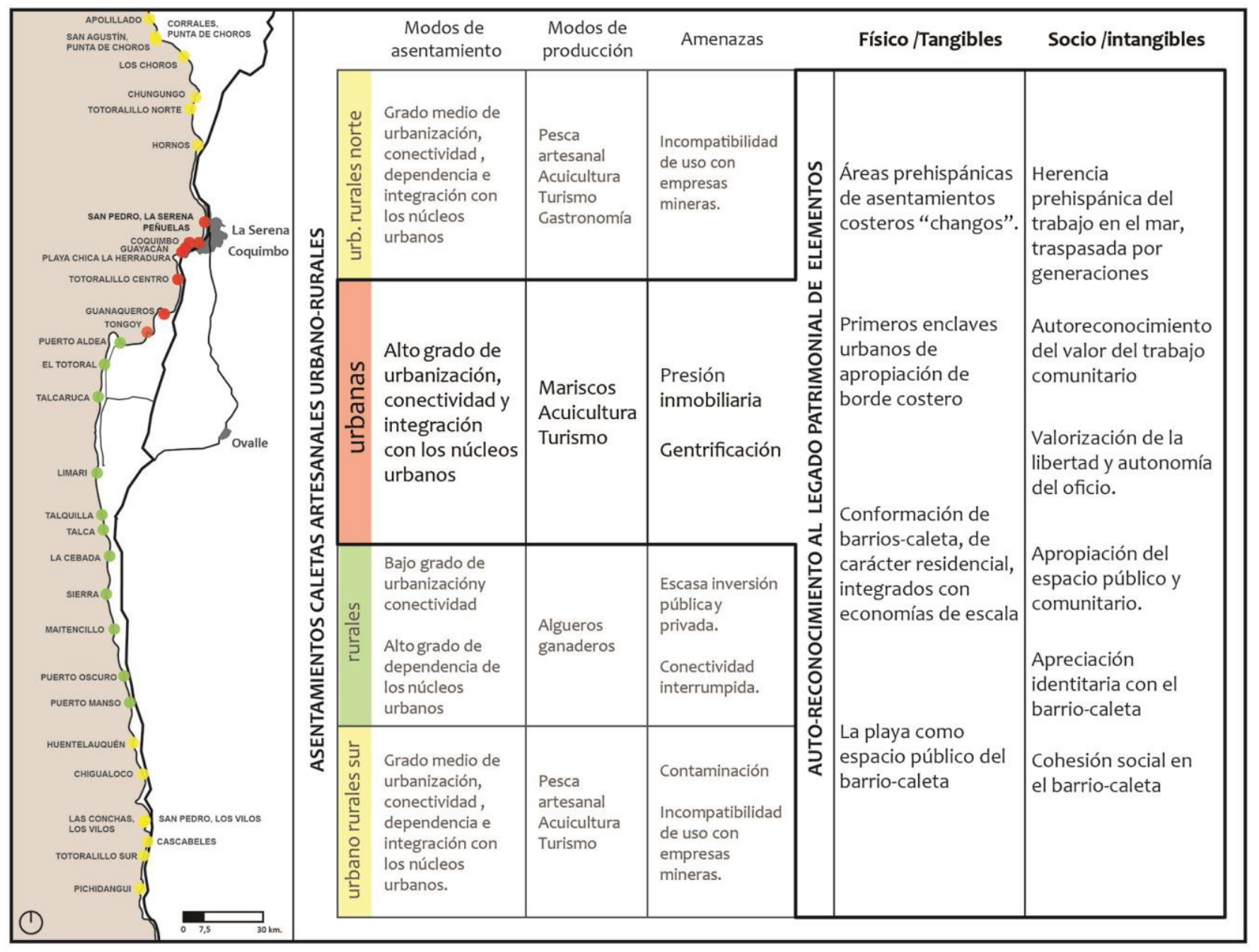

Fig. 1 Sistema de ocupación del borde costero de la IV región de Coquimbo. Fuente: Elaboración propia. 


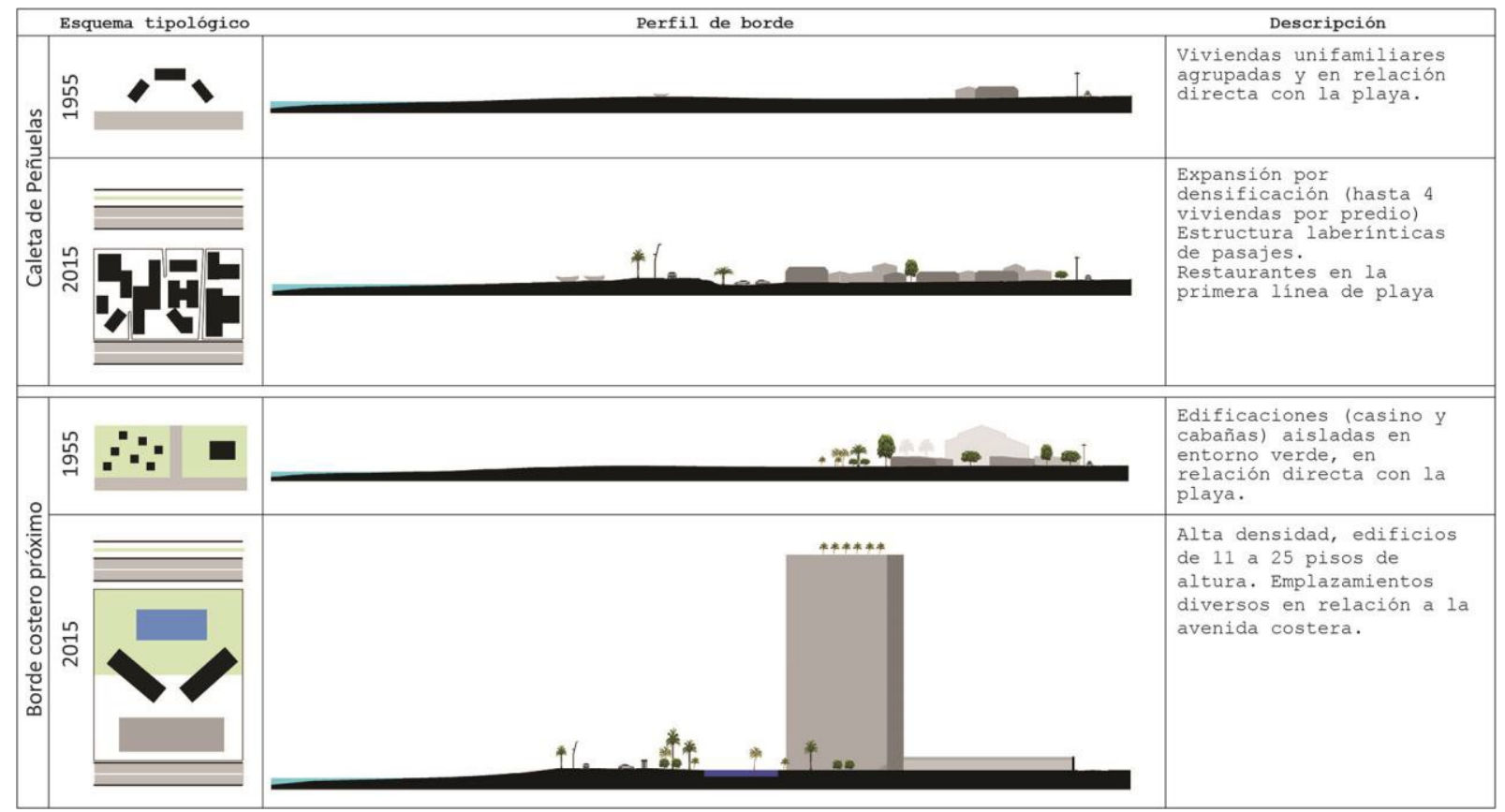

Fig. 2 Tipologías de ocupación de borde en la caleta de Peñuelas Fuente: Elaboración propia.

Considerando estas grandes transformaciones del sistema urbano en las que se ven inmersas, llama la atención que las caletas de Peñuelas y San Pedro conserven cierta identidad y valores propios, con una comunidad activa, organizada y autoconsciente de su patrimonio. Si bien son barrios de estrato social bajo, pertenecientes al grupo socioeconómico " $D$ ", no manifiestan los mismos problemas y conflictos que sus correspondientes que residen en un barrio de vivienda social contemporánea.

A partir de estas observaciones surgen las siguientes preguntas: ¿Cuál es la incidencia del grado de integración urbana en el desarrollo comunitario de las caletas y la prevalencia de sus valores patrimoniales?, ¿Qué importancia tiene su economía a escala humana (Max-Neef, 2006) en la construcción de su espacio habitado? y ¿Cuál es el grado de reconocimiento y aprecio que manifiestan sus habitantes por su patrimonio material e intangible? (McGoodwin, 2002).

Por tanto, la investigación tiene como propósito indagar en las relaciones que establecen las comunidades con la caleta y su entorno, la incidencia del proceso de integración al sistema urbano y la valoración que los habitantes hacen de su espacio habitado, identificando los elementos formales y espaciales más valorados y apropiados por sus habitantes, los elementos de identidad comunitaria y su soporte contextual.

\section{Metodología.}

En una primera parte del estudio se recolectaron datos de fuentes primarias y secundarias, como bibliografía existente, planimetrías actualizadas e históricas, registros fotográficos actuales e histórico y entrevistas semiestructuradas a actores clave del ámbito gubernamental y académico. Luego, en una segunda parte, estos datos se complementaron con técnicas de trabajo de campo mediante la observación y análisis espacial del área de estudio. 
Para el análisis espacial, se realizó un estudio de las evidencias físicas del proceso de aproximación geográfica entre los núcleos urbanos consolidados de La Serena y Coquimbo hacia las localidades de Peñuelas y San Pedro y se identificaron los aspectos morfológicos característicos de cada una.

En el trabajo con las comunidades se empleó el método de observación participante en las actividades diarias de las caletas analizadas, entrevistas estructuradas a residentes y entrevistas en profundidad a actores locales originarios. La información levantada se analizó mediante la metodología de análisis de discurso (Canales, 2006). Además, las entrevistas proporcionaron indicadores de movilidad urbana de sus habitantes, las que dieron luces del grado de interrelación alcanzado por estas comunidades con el sistema urbano del Gran La Serena.

Por último se extrajeron algunas conclusiones respecto a la valoración que estás comunidades tienen de su patrimonio material e intangible, caracterizando los espacios y aspectos más valorados.

\subsection{El caso de estudio}

La Bahía de Coquimbo, escenario geográfico principal del desarrollo urbano del Gran La Serena, es el emplazamiento de tres caletas de pescadores artesanales, Coquimbo, Peñuelas y San Pedro. Estos asentamientos costeros de las caletas de pescadores y recolectores artesanales están localizados desde tiempos prehispánicos (Castillo, 1989). La Cultura Animas, ascendiente de la cultura Diaguita, ocupó una parte del norte semiárido, desde el valle de Copiapó hasta los Valles de Hurtado, Limarí, incluyendo un asentamiento permanente en la Bahía de Coquimbo. Las fechas calculadas para estos asentamientos datan entre el 800 y 1200 d.C. (Ampuero, 1978).

La caleta de Coquimbo, emplazada en la playa Changa (Fig. 3), configuró inicialmente un poblado de pescadores en directa relación con la playa. Pero después de su destrucción por el maremoto de 1922, sus habitantes se reubicaron en distintos puntos de tejido urbano, quedando totalmente integrada a la ciudad.

Este estudio se concentra en las otras dos caletas, Peñuelas y San Pedro, que han tenido una relación próxima con los núcleos urbanos, pero se han conformado como asentamientos con una estructura propia. Ambas están emplazadas frente a bancos naturales y cuentan con áreas de manejo para la extracción de mariscos, en específico el recurso macha (Fig. 3).

En estas localidades se fueron estableciendo comunidades rurales, organizadas socialmente a modo de clanes familiares, manteniéndose hasta mediados del siglo XX en una condición de asentamiento precario. El Plan Serena entre 1948 y 1952 modificó fuertemente su entorno y moldeó su morfología y configuración actual como caletas urbanas.

A partir de la década de 1980, en contexto de la conurbación de La Serena y Coquimbo (Véliz, 1995), se urbaniza el borde costero de la bahía con la construcción de la Avenida del Mar en la comuna de La Serena y la Avenida Costanera en la comuna de Coquimbo.

En el borde costero las nuevas tipologías de edificación se caracterizan por volcar sus espacios comunes hacia el interior de los recintos. En los proyectos desarrollados se observa que la vista al mar pasa a ser el factor más importante a la hora de diseñar y se han edificado muros frontales al mar, paralelos a la calle, de entre 7 y 12 pisos de altura en La Serena y, en una segunda etapa, de hasta 25 pisos en Coquimbo (Fig. 4). Estas nuevas tipologías tensionan el diseño del espacio urbano del borde, generando una barrera infranqueable entre el espacio público de la Av. Costanera y la playa con los espacios privados comunes de los nuevos barrios verticales. 


\section{URBANISMO}

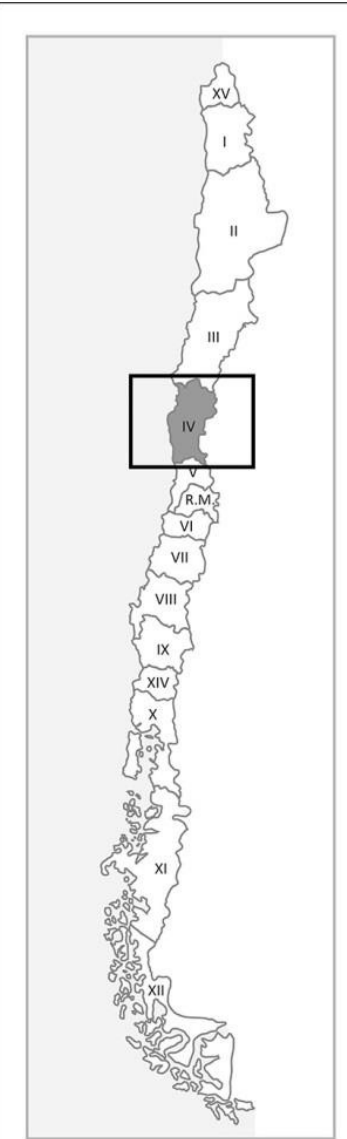

CHILE CONTINENTAL

Superficie: $756.102,4$ km2 Población: 16.572.475 hab.

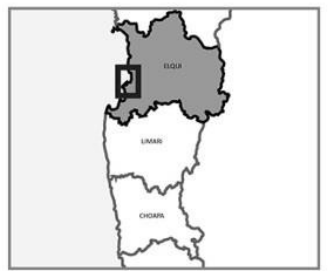

IV REGIÓN DE COQUIMBO

Superficie: $40.580 \mathrm{~km} 2$

Población: 603.210 hab.

Área provincia Elqui

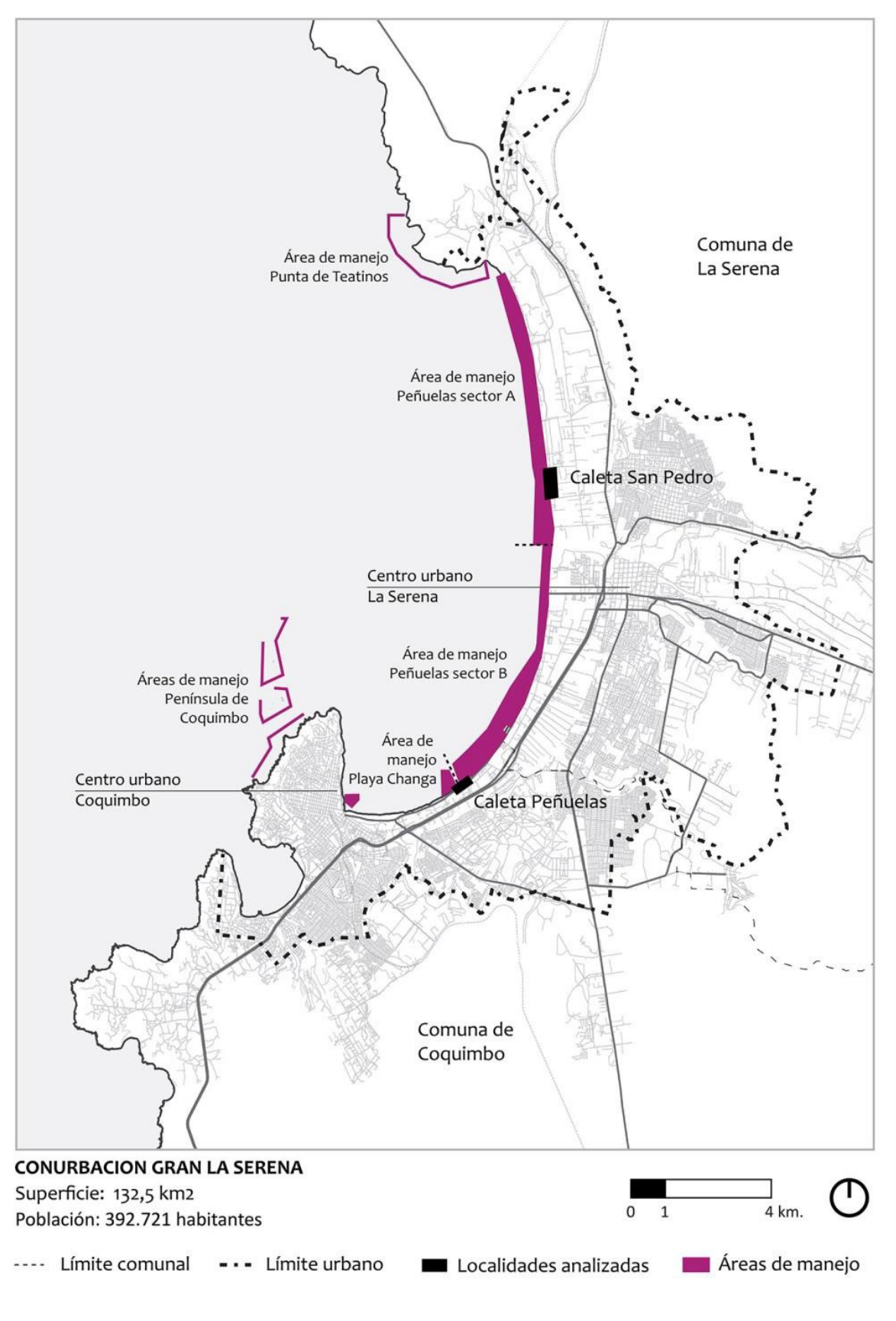

Fig. 3 Presentación área de estudio Fuente: elaboración Propia. 


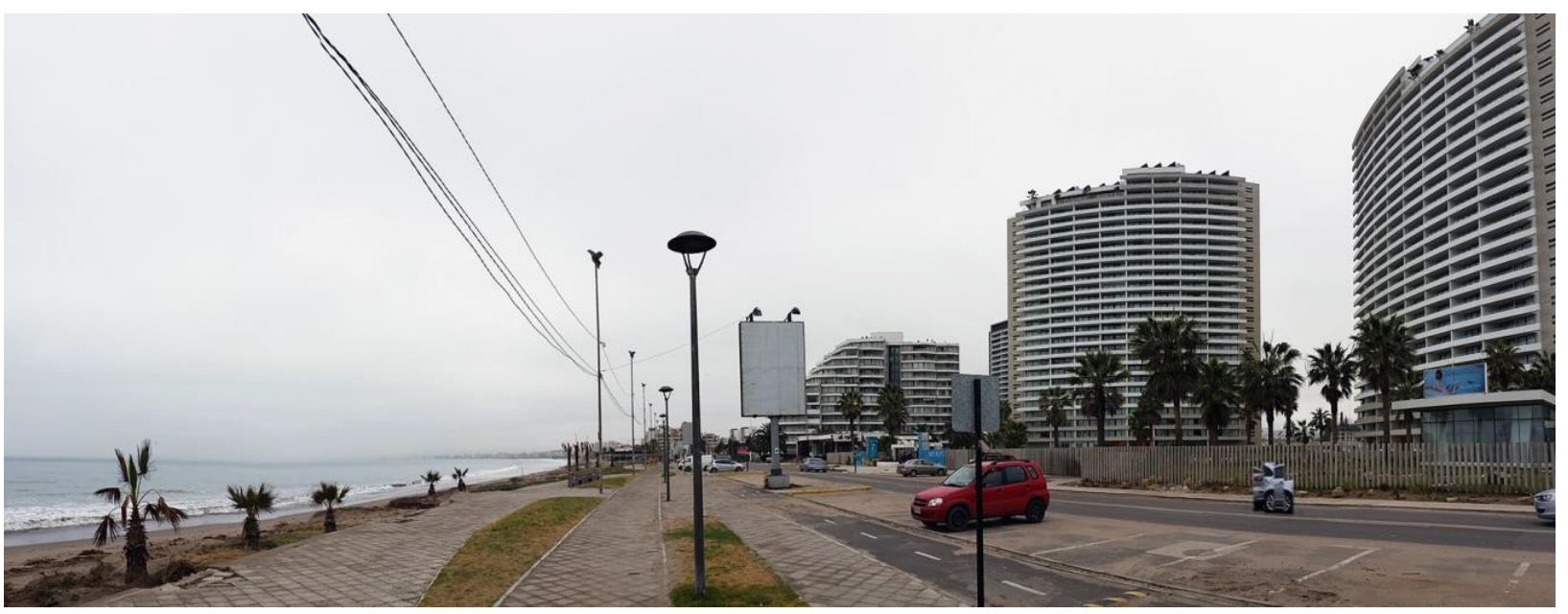

Fig. 4 Grandes conjuntos de edificación en altura en el borde costero de la bahía de Coquimbo.

Fuente: Archivo personal de los autores

Para el caso analizado de caleta San Pedro, si bien el plan regulador de La Serena limita la edificación en altura en el polígono de la caleta, se evidencia como un agente de vulnerabilidad la presión ejercida por la inversión inmobiliaria en los alrededores de la misma. Esta se hace presente en el sector norte con la construcción de dos conjuntos de viviendas unifamiliares en extensión, destinados a un grupo social de clase media, con precios que inician en 1.600 UF (Fig. 5).

Los terrenos ubicados hacia el norte de la caleta son propiedad de una empresa inmobiliaria, la cual está en la tercera etapa de ejecución del proyecto Serena Golf, construyendo un conjunto de condominios cerrados, viviendas en altura y unifamiliares orientados a estratos socioeconómicos C2 y $A B C 1$. Éstos están ubicados en primera línea de playa, frente a las zonas de bancos naturales de extracción. El lugar experimenta un cambio en su vocación original del tipo rural-suburbana hacia expansión urbana en extensión. En este caso, la integración urbana se está produciendo de un modo fragmentado, por adición de paños urbanizados dispersos, más que por continuidad del espacio urbano.

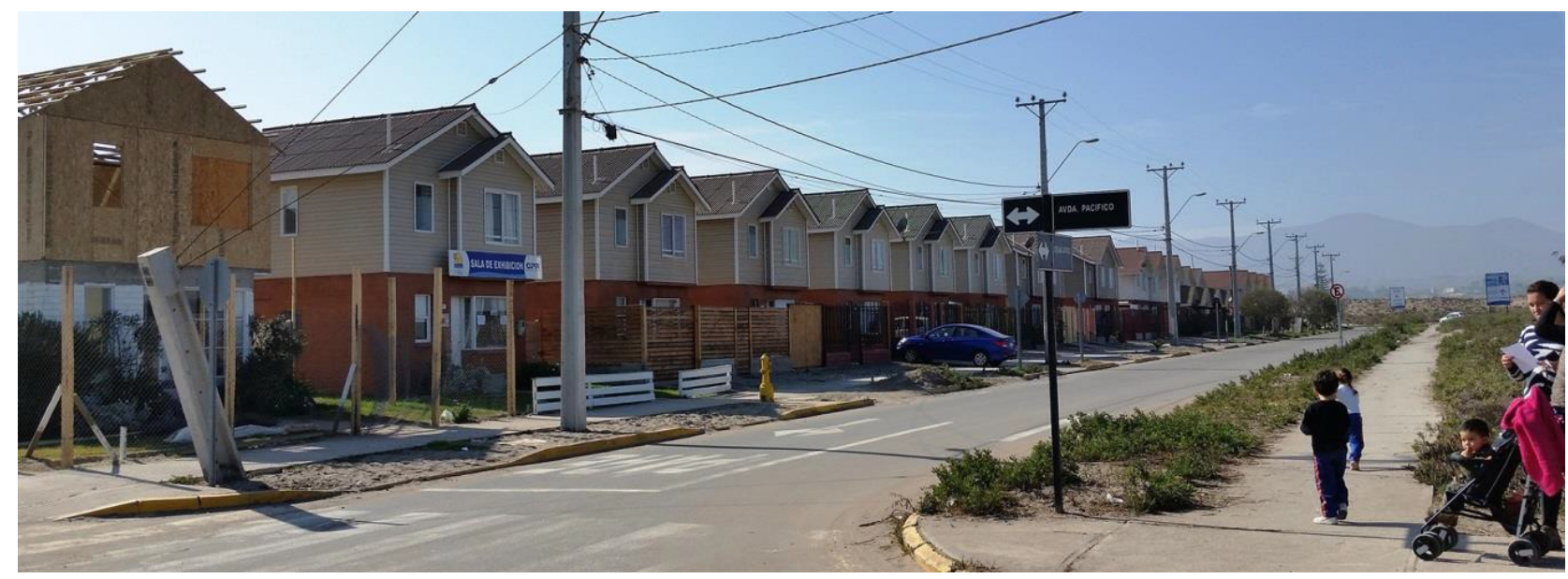

Fig. 5 Conjunto de viviendas, oferta inmobiliaria sector norte Caleta San Pedro.

Fuente: Archivo personal de los autores. 


\subsection{Dimensiones socio-espaciales del barrio caleta Peñuelas}

Escritos registrados en el periodo colonial español mencionan de asentamientos pesqueros de origen prehispánico junto a esteros y humedales, con conocimientos de las técnicas en torno a las faenas del mar. Estos saberes eran traspasados oralmente de generación en generación. Al interior de las comunidades existían clanes familiares, los cuales tenían una diversificación del trabajo dentro de su estructura social. La participación colectiva de la mujer, hombres y niños en la actividad productiva se estructuraba de modo solidario y se denominaba mita o mingaco. Sus viviendas eran construidas de material ligero, con estructuras de madera, generando envolventes de sus contornos y cubiertas con una especie vegetal tipo junquillo, llamado totora, la cual estaba presente en las zonas de humedales generadas en las desembocaduras de los cursos de agua (Cerda, 2013).

Es la condición histórica ancestral del pueblo Chango (nombre genérico otorgado a los pueblos originarios del borde costero del territorio norte), que partiendo como un modo de supervivencia, se transformó en un sistema de socio-cultural de extracción local de los recursos del mar, dando origen y forma a los modos de habitar el borde costero.

Con la llegada de los colonos españoles, la etnia local de origen fue absorbida como mano de obra a modo de encomiendas para los conquistadores, y posteriormente para las misiones y latifundios existentes a cargo de la iglesia Católica (Concha, 1871).

En la actualidad se puede reconocer a familias de origen dedicadas a este oficio, las cuales, desde principios del siglo pasado se establecieron espontáneamente con viviendas de estructuras livianas en terrenos ubicados entre las dunas y los humedales de Peñuelas. A los habitantes de este asentamiento de pescadores/recolectores se les llamaban "Los Totora" debido al material característico con el cual construían sus casas. Estas familias fueron el origen de lo que hoy es la Caleta de Peñuelas.

Entre los años 1946 y 1952, bajo la restructuración urbana que implicó el Plan Serena, amplios sectores de vegas de la primera terraza costera fueron desecados, parcelados y otorgados a inmigrantes italianos. Las familias pertenecientes a la Caleta Peñuelas fueron reubicadas casi un kilómetro al sur desde su localización original junto a la vertiente Canto del Agua hacia una población con viviendas sociales y equipamientos, quedando situados en su actual localización (Fierro Page, 2015) (Fig. 6). El traslado posibilitó la continuidad del proyecto urbano-turístico iniciado con el Casino de Peñuelas en 1934, a través de la construcción de un complejo de cabañas de veraneo llamadas Las Cabinas (González Videla, 1975).

El asentamiento construido para los pescadores estaba conformado por una decena de volúmenes agrupados en torno a patios abiertos y con directa relación con la playa. Esta estructura aún es observable en la morfología actual de la caleta (Fig. 6), compuesta principalmente por viviendas unifamiliares, de uno a dos pisos de altura. La volumetría original se ha densificado por crecimiento al interior de los lotes, en los que es posible encontrar de 4 a 5 viviendas. Se conforman estructuras laberínticas al interior de estos (Fig. 7).

Dentro de esta densidad y escasez de espacios libres dentro de los lotes, se advierte los habitantes han volcado actividades familiares a los pasajes interiores de la caleta, conformándose como espacios semipúblicos que la atraviesan transversalmente. Estos lugares característicos se destacan como espacios para el encuentro de los vecinos (Fig. 8). 


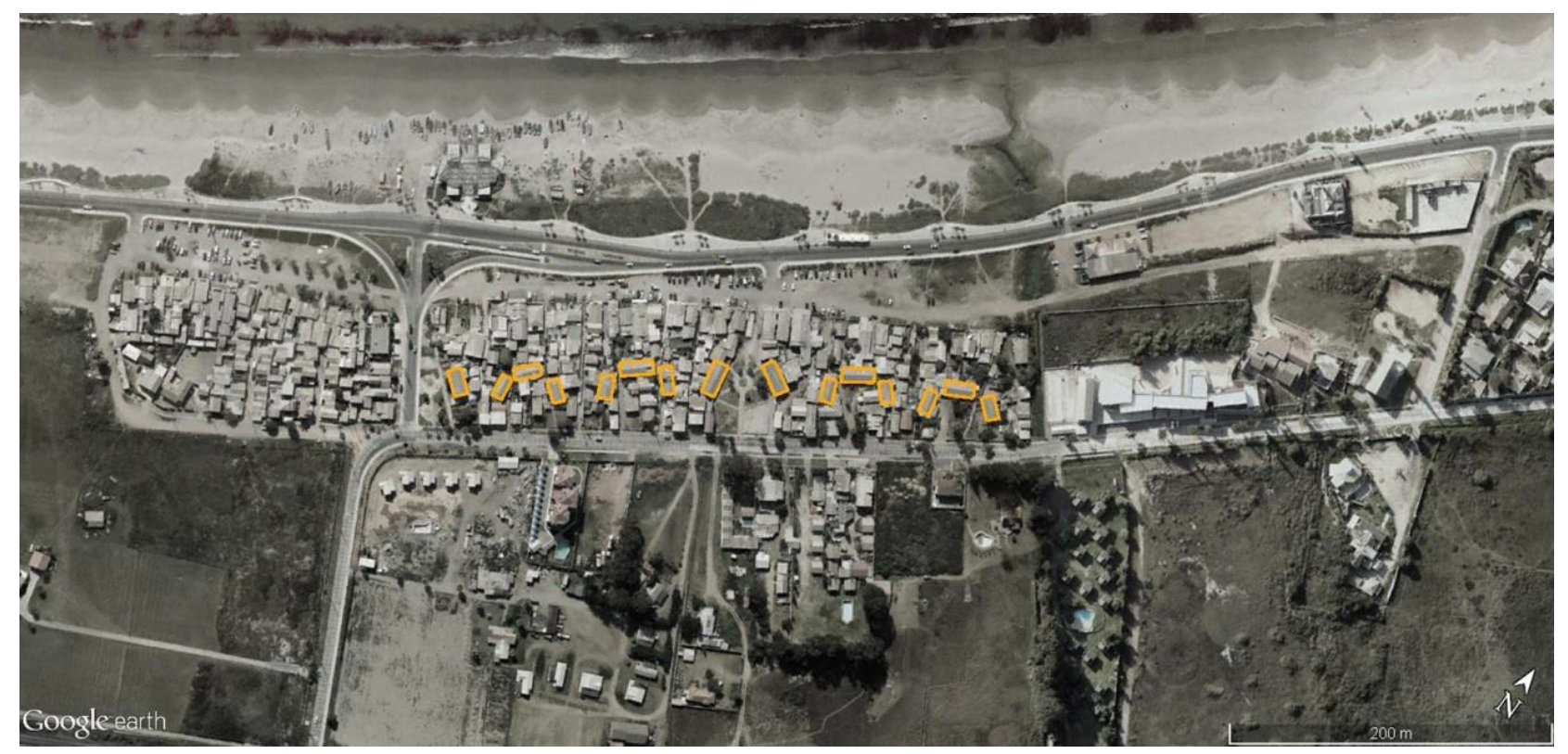

Fig. 6 Asentamiento original de la caleta de Peñuelas (en color) sobre imagen satelital (año 2012).

Fuente: Elaboración propia en Google Earth.

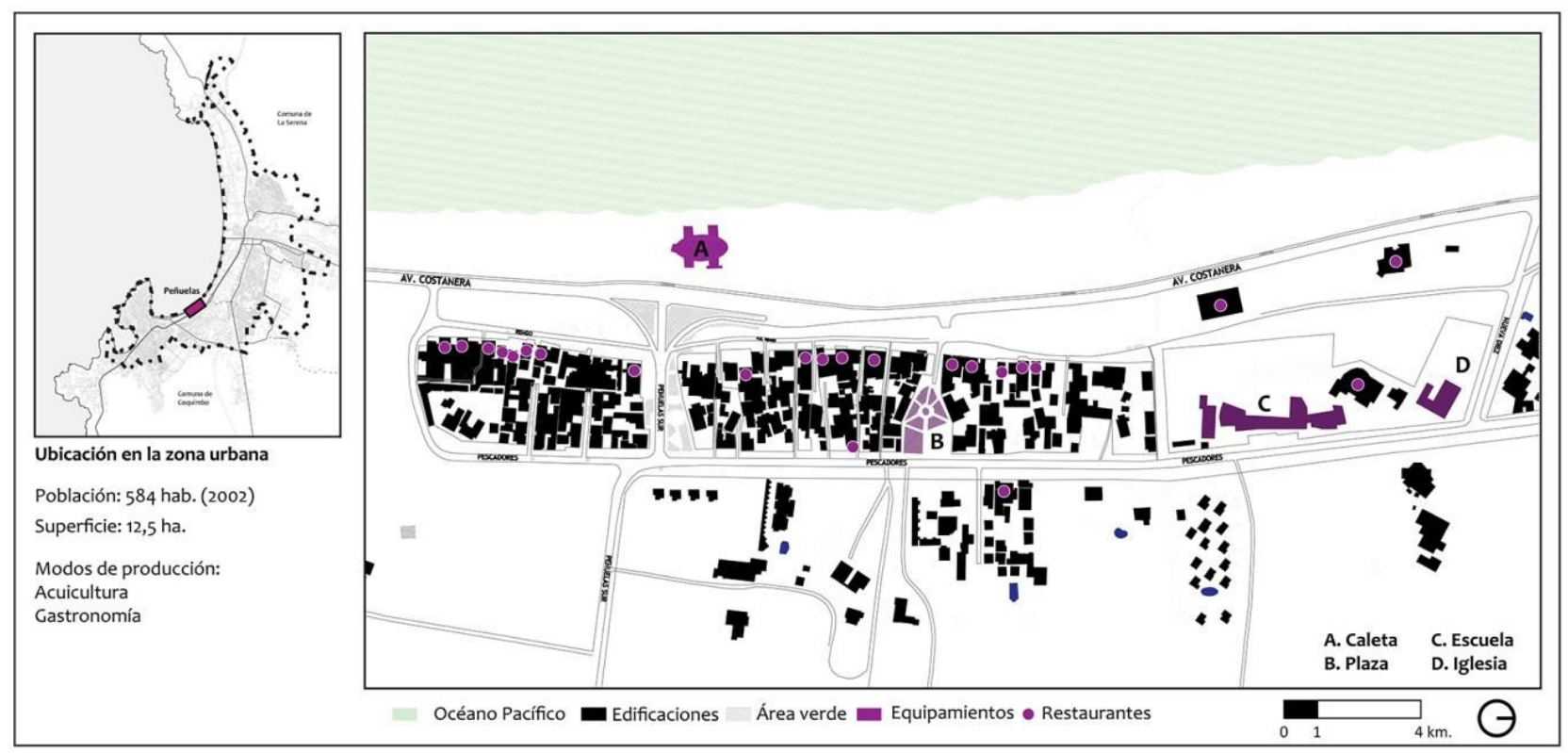

Fig. 7 Plano de la caleta de Peñuelas

Fuente: elaboración propia. 


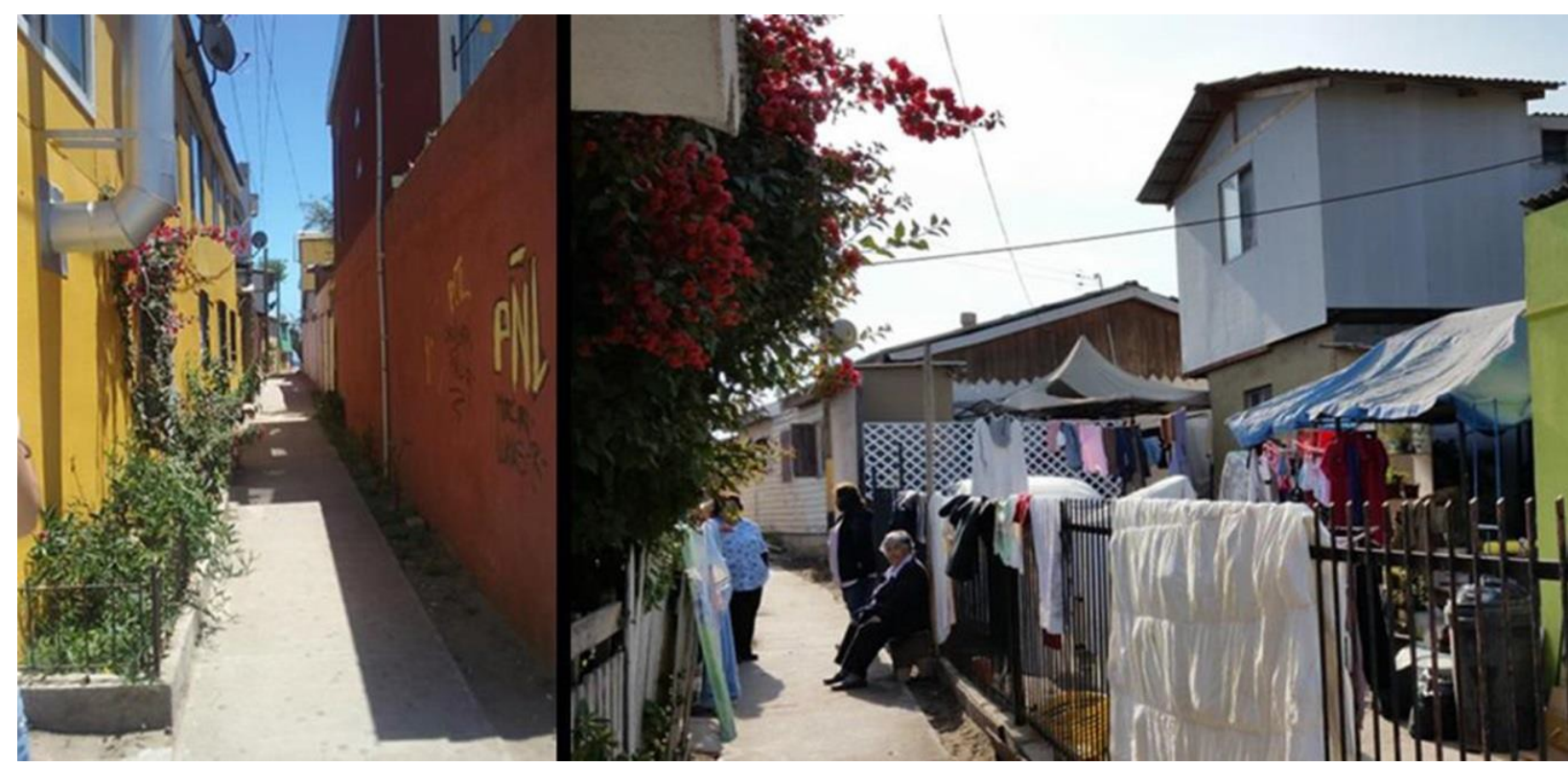

Fig. 8 Espacios peatonales de la Caleta de Peñuelas

Fuente: elaboración propia en base a archivo personal de los autores.

En torno a la primera línea de viviendas de la caleta, se distingue un proceso de transformación de la vocación original de espacios residenciales íntimos. Las viviendas han sido reacondicionadas como unidades productivas y dispuestas como restaurantes o "picadas". Este modo de habitar el espacio residencial común, conjugando habitación con actividad productiva aparece como un elemento fundamental en la configuración actual de la Caleta. En su conjunto conforman una fachada comercial de línea continua hacia la costanera (Fig. 9). La mayor parte de estos establecimientos productivos pertenecen a las familias de la caleta, los cuales comenzaron como pequeñas cocinerías. Hoy, muchos de ellos están consolidados como restaurantes especializados, con productos típicos de la zona.

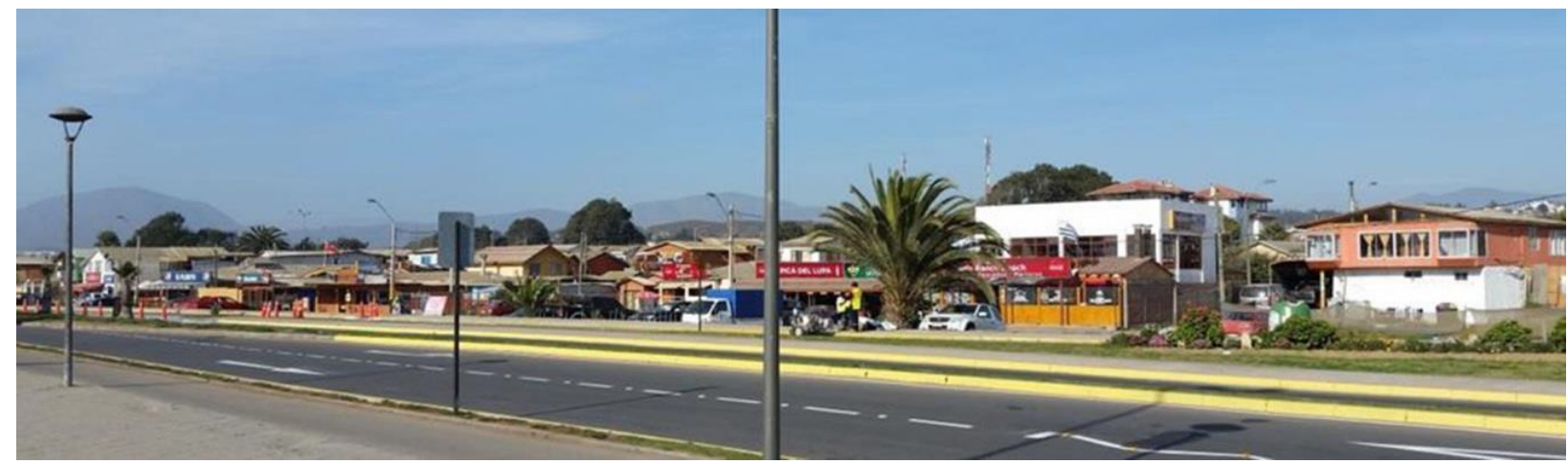

Fig. 9 Frente comercial Caleta Peñuelas, Coquimbo

Fuente: archivo personal de los autores.

Es en este espacio, donde el barrio caleta se vuelca hacia fuera, tornándose un espesor permeable de carácter público hacia la ciudad, un espacio generoso, que invita a la permanencia y permite recorridos (Pozueta, Lamíquiz y Porto, 2009). 
En el sector de playa, frente a los locales gastronómicos y viviendas, se localiza la infraestructura de los mariscadores y los respectivos botes, constituyéndose en el centro productivo del quehacer del barrio. En todo el ancho de playa se despliegan los arpegios de pesca, en un acto de conquista espacial del borde (Fig. 10).

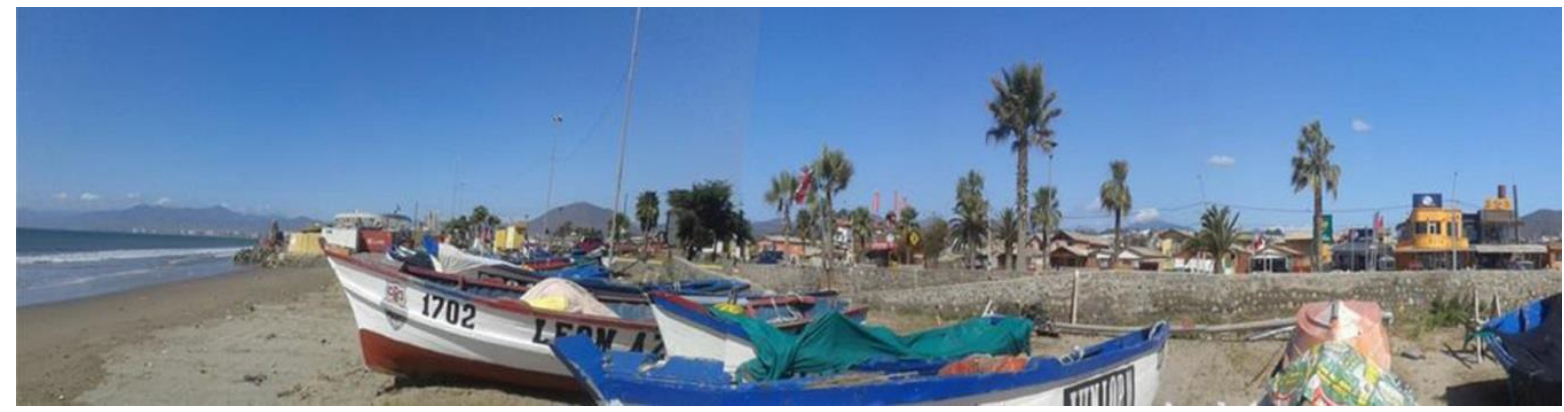

Fig. 10 Ocupación de la playa por la actividad productiva en la caleta de Peñuelas

Fuente: archivo personal de los autores

Ante esta apertura hacia la ciudad, la actividad laboral de la caleta es atravesada, recorrida y permeada por el transeúnte, regalando al espacio público la actividad propia del quehacer de esta comunidad. Se reconoce como un valor importantísimo este espacio costero que integra los aconteceres urbanos con el quehacer cotidiano de la actividad de la caleta. Este lugar se constituye como un escenario urbano representativo, local y vivo, develando a lo público la vocación originaria de la comunidad costera.

\subsection{Dimensiones socio-espaciales del barrio caleta San Pedro.}

Desde la rivera norte de la desembocadura del rio Elqui hasta el humedal laguna Saladita de Punta Teatinos, se desarrolla el área de manejo de la caleta San Pedro, siendo el humedal ubicado al norte de la bahía un lugar preferido para las pesquerías de origen chango. La Caleta se ubica dos kilómetros al norte del río (Fig. 2). De origen rural, se integró dentro del área urbana a partir del Plan Regulador Comunal de La Serena del año 1992.

Antiguamente, este lugar se llamaba Población La Playa, asentamiento espontáneo que se generó en este sector a partir del año 1854, cuando se establecen en el lugar cuatro familias: los Velásquez, los Munizaga, los Contreras y los Godoy. Estas familias se instalaron para dedicarse a la extracción de productos del mar. Sus viviendas fueron construidas de material ligero en rucos de piedra y adobe con cubiertas de totora. En 1930 se instaló una capilla con una imagen de San Pedro y entonces esto pasó a llamarse caleta San Pedro. El año 1948, el gobierno de Gabriel González Videla, les entregó títulos de dominio de los terrenos a los pobladores de la localidad (Diario El Día, 2013).

El asentamiento presenta una estructuración que da cuenta de una parcelación determinada desde la administración estatal como una solución funcional: manzanas ortogonales, baja densidad, lotes regulares cerrados con pandereta y vías que privilegian el automóvil, sin que se observe la conformación de espacios urbanos significativos. La mayoría de las viviendas corresponden a casetas básicas de subsidio rural otorgado por el Estado. Con el paso de los años estas viviendas se han modificado a través de ampliaciones y se han construido segundas viviendas al interior de los sitios, si bien todavía se observa un equilibrio entre lo construido y el espacio libre de los lotes (Fig. 11).

Actualmente se observa una localización espacial distante con el centro de la ciudad, una relación más cercana con el sector rural, y una relación visual con el sector periférico de la ciudad población Las Compañías. 


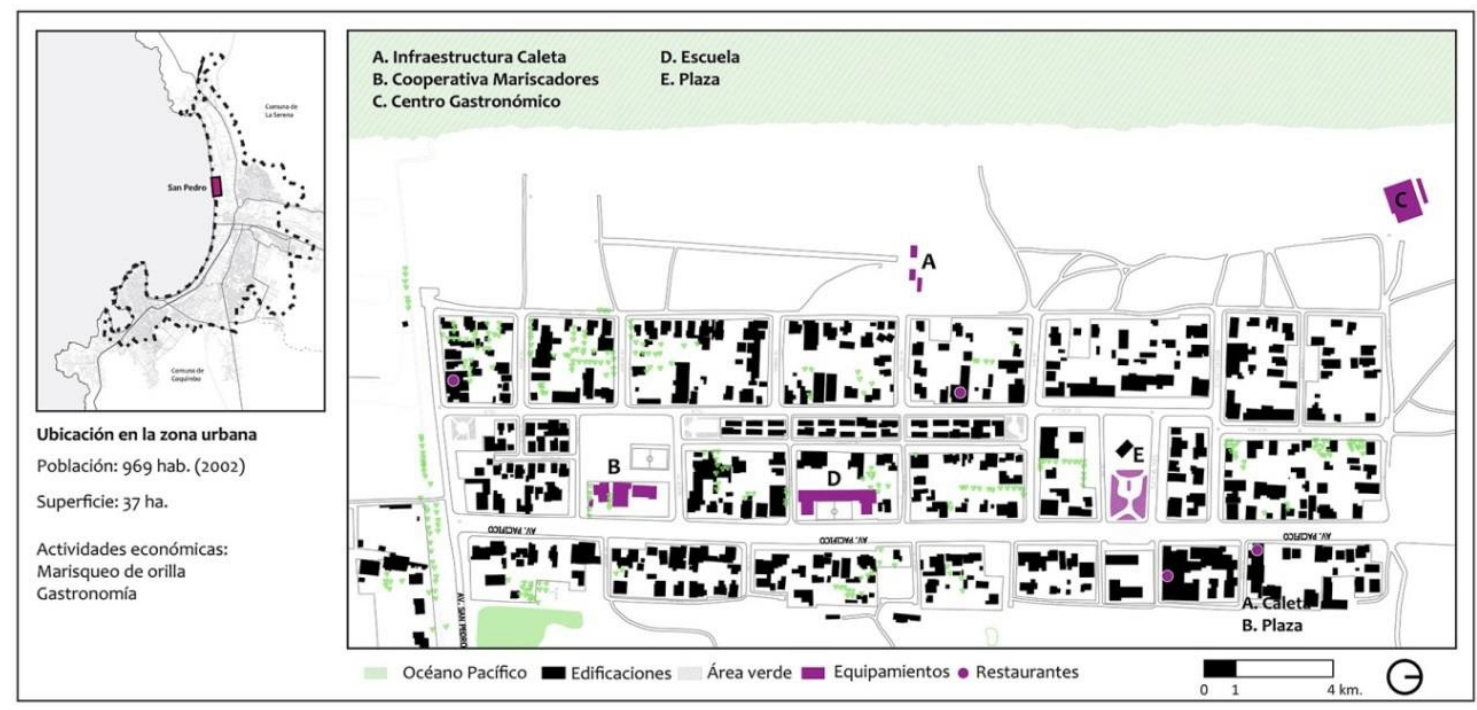

Fig. 11 Plano de la Caleta de San Pedro.

Fuente: elaboración propia.

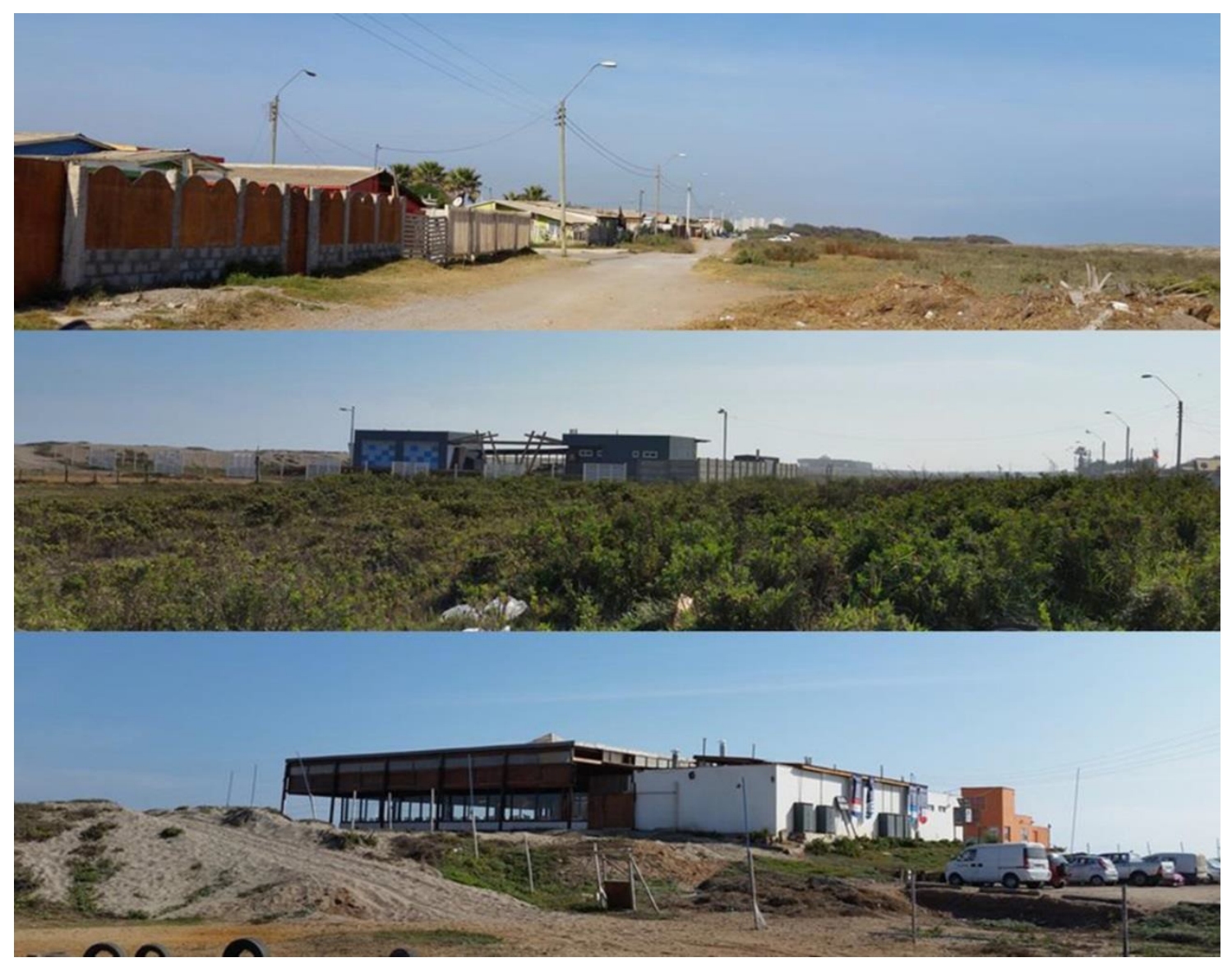

Fig. 12 Frente costero de la Caleta San Pedro.

Fuente: elaboración propia en base a archivo personal de los autores. 
El barrio posee equipamientos propios, como lo son la escuela, la iglesia y la plaza. El borde de la playa, que no está urbanizado, se reconoce como un espacio público abierto, donde se desarrollan las actividades de extracción de mariscos. Ubicada frente a la población y al centro de la playa está el equipamiento de los mariscadores; al costado norte, el centro gastronómico que concentra la oferta de servicios gastronómicos a los visitantes y turistas (Fig. 12).

Se observa un marcado contraste entre la espacialidad del asentamiento y el borde costero, constituyendo el frente construido en un borde indefinido y escasamente habitado. La playa aparece como un espacio aparte de la localidad y las manifestaciones del quehacer productivo son más bien escasas.

Algunos restaurantes, en particular el centro gastronómico (Fig. 11), concentran las instancias de interacción entre los habitantes y los visitantes a la Caleta, sin que logren configurar recorridos 0 circuitos urbanos.

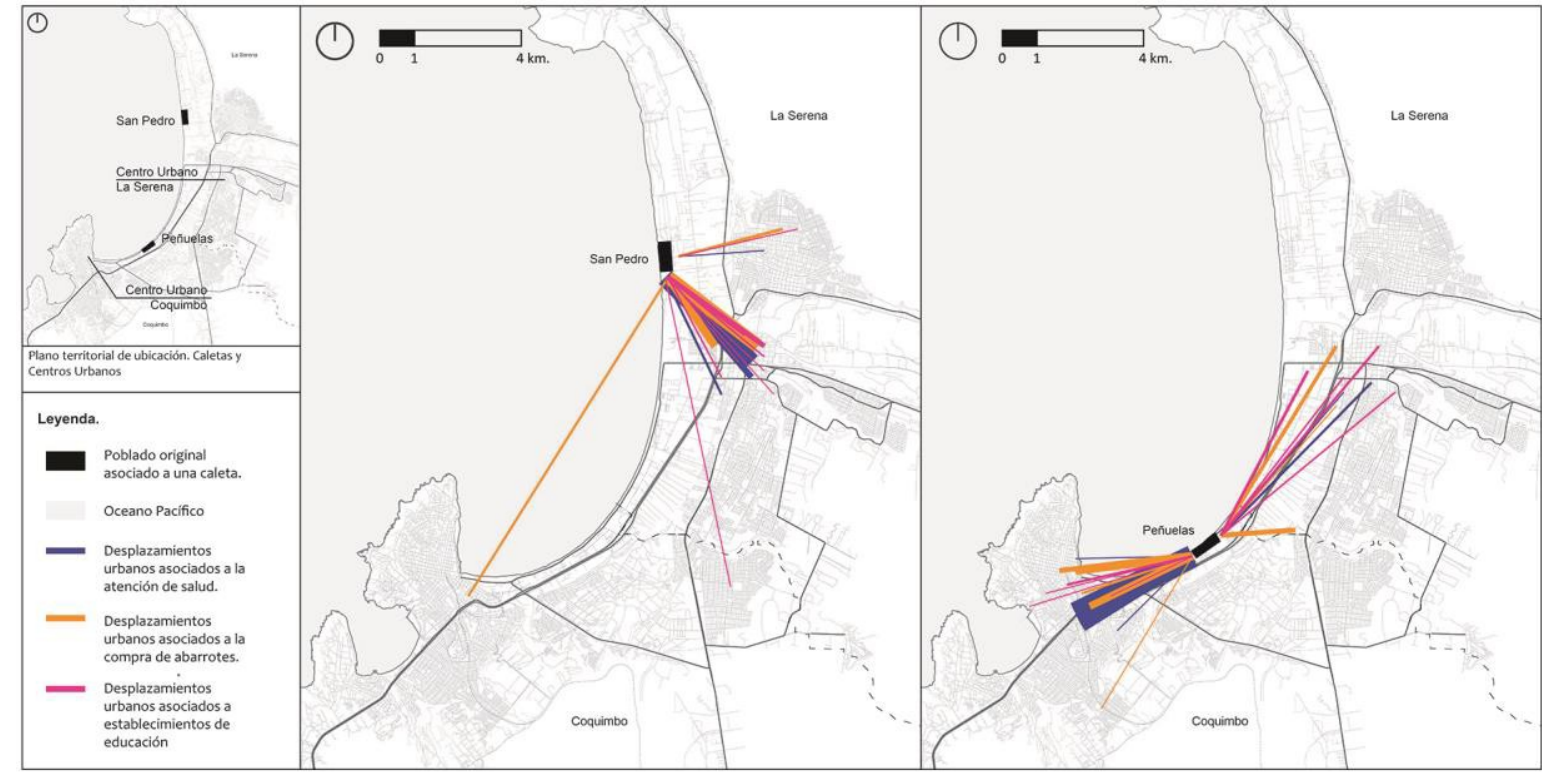

Fig. 13 I ntegración funcional de las caletas urbanas del Gran La Serena

Fuente: Elaboración Propia.

\section{Grado de integración urbana caletas urbanas}

A través de las entrevistas estructuradas realizadas a los habitantes de ambas caletas se pudo perfilar el comportamiento de integración funcional por parte de los sus habitantes. En ambos casos tienen una movilidad continua hacia los centros de las comunas a la que pertenecen (Fig. 13). La mayoría de los casos declaran movilidades de una vez por semana y un segundo grupo, por motivos educacionales, movilidades diarias de desplazamiento.

San Pedro, situada al noroeste de La Serena, con la desembocadura del río al sur y una única conexión con la ruta 5 como vía de acceso, ha establecido una relación de integración espacial de conectividad y movilidad casi exclusivamente con el sector céntrico de Serena. Se observa una fuerte tendencia de concentración funcional en los desplazamientos vinculados al comercio, estrechamente relacionada a la precariedad medios de transporte, tan sólo una línea de taxicolectivos que conecta la localidad con el centro de La Serena.

Peñuelas, por su parte, al estar emplazada en el punto medio entre las dos ciudades, muy próxima a la carretera panamericana y con varias vías de comunicación con la ciudad, presenta 
una doble relación, la que se ha especializado de acuerdo a dependencias administrativas y la oferta de bienes y servicios de los dos centros urbanos. Por un lado, se observa una intensa relación de desplazamientos por motivos de salud hacia Coquimbo, comuna de la que depende en términos administrativos y por otra parte, el centro de La Serena concentra las preferencias en materia educacional. Los desplazamientos asociados a consumo se dividen de forma equivalente, siendo el centro de Coquimbo un lugar de abastecimiento de alimentos y La Serena preferido para compras de otros bienes. Esta doble integración, dada su localización espacial en el límite de las dos comunas le otorga una nueva dimensión de centralidad con respecto a la totalidad del sistema urbano (Fig. 13). La caleta de Peñuelas, además, se ha consolidado como un centro gastronómico de primera importancia en el borde costero, muy próxima a centros de eventos, e inserta en el sector temático bohemio y turístico de la Avenida del Mar - Costanera.

\section{Percepción de barrio y valoración del patrimonio}

A pesar de las transformaciones socio-espaciales experimentadas por las comunidades de origen de ambas caletas y su rápida integración al sistema urbano en los últimos 20 años, se destaca, aunque en distinto grado, la prevalencia de una esencia cultural en el modo de habitar de estas comunidades generada por la conjugación del trabajo integrado a la habitar los espacios de la vida cotidiana. En el análisis de discurso en base a las entrevistas realizada en las caletas, se identificaron patrones de auto identificación y de valoración, que en su conjunto representan el patrimonio socio-espacial de aspectos intangibles que prevalecen en estas comunidades.

Valoración y sentido de pertenencia del lugar habitado.

Los habitantes originales, nacidos o que han vivido la mayor parte de su vida en estas comunidades, en su mayoría son hijos de familias de pescadores de más de tres generaciones, aún mantienen relación directa con el trabajo relacionado a las actividades cotidianas de la caleta y manifiestan un fuerte sentido de pertenencia y arraigo con el espacio habitado. Conciben el espacio de intimidad de sus viviendas y el espacio comunitario del trabajo como un conjunto indisoluble, destacan la cercanía y tranquilidad que les otorga su entorno laboral y el estar cerca de sus familias, atribuyendo al espacio cotidiano una sensación de libertad, tranquilidad y felicidad, reconociéndolos lugares bellos y seguros.

Cuando se les pregunta por su espacio de trabajo y la apreciación del entorno, los espacios públicos más destacados son: la plaza, la playa y la caleta, otorgándoles significaciones de gran valorización en varios casos declaran que el mar, la playa y su trabajo "lo es todo" para ellos, reconociendo estos aspectos como elementos formadores de su persona y de sus vidas.

Trabajo en comunidad y la transmisión familiar del oficio.

Un segundo aspecto destacado en las entrevistas es el sentido de valoración que otorgan las personas a sus grupos de trabajo. El sentirse pertenecientes a una comunidad organizada entorno a la actividad laboral les genera arraigo social como grupo. En su mayoría se identifican como partes de un total, declaran sentirse felices y queridos por el resto. El alto grado de valoración hacia el gremio que los contiene es generalizado en las apreciaciones individuales.

Cuando se les pregunta sobre el aprendizaje de su oficio, los entrevistados declaran haber aprendido las artes recolectoras a una edad temprana entre los 7 a los 15 años. El significado de integración de la comunidad con los distintos grupos etarios refuerza la cohesión social que prevalece en la caleta, las artes de recolección son enseñadas por la propia familia de generación en generación. Los niños aprenden el oficio a modo de juego, a medida que se van 
haciendo adultos tienen mayor grado de responsabilidad dentro del quehacer del trabajo comunitario.

Surge en este punto la pregunta sobre la posibilidad de una generación perdida, es decir, un grupo generacional joven, con formación técnica o profesional, que al haberse insertado en el mercado laboral de la ciudad, no participa dentro de las actividades comunitarias cotidianas. Este fenómeno no se observa con total claridad dado que los jóvenes que salen de la caleta mantienen la herencia del oficio, suelen trabajar por temporadas o en situaciones de inestabilidad laboral retornar a la comunidad. Se reconoce, en cualquier caso, como aspecto crítico a evaluar en futuras etapas de la investigación.

\section{Consideraciones finales}

Las caletas urbanas de la bahía de Coquimbo se han estructurado a partir de intervenciones estatales sobre comunidades preexistentes que han configurado poblados con equipamientos y espacios significativos para sus habitantes. Estas se han densificado de acuerdo a procesos generacionales y la relación con el sistema urbano influye en la complejidad de su economía y su estructura espacial.

Cabría suponer que ante el mayor grado de integración que configuran sus relaciones urbanas, y la falta de protección en la normativa urbana respecto de su espacio de residencia y trabajo, la caleta de Peñuelas hubiese visto amenazada su identidad patrimonial, y ya debiese manifestar fenómenos de homogenización con el resto del paisaje urbano costero. Sin embargo, el sector conserva rasgos identitarios muy marcados y sus habitantes un fuerte sentido de pertenencia y valoración su espacio habitado. Estas manifestaciones son más contundentes en Peñuelas que en San Pedro, que presenta un menor grado de integración física y funcional al sistema urbano.

Por tanto, los resultados obtenidos indican una fuerte relación entre el grado de integración física y funcional de las caletas en el sistema urbano con sus manifestaciones identitarias, mostrando que a mayor integración urbana, se observa una comunidad más desarrollada, con manifestaciones culturales más explícitas y una fuerte apropiación comunitaria del espacio público.

Ambos casos conservan cualidades formales originales como barrios históricos costeros en el contexto de la bahía. Una imagen de barrio que se construye y sustenta en sus modos de vida y una fuerte correlación entre la actividad económica familiar y la forma del espacio habitado como base de sus valores patrimoniales.

Se han identificado tres aspectos clave en relación a esta prevalencia. El primero de ellos es la relación estrecha entre residencia y actividad productiva que propicia un uso intenso del espacio común, la apropiación del oficio de este espacio y la ocurrencia de actividades diversas en él. Los valores patrimoniales de las caletas urbanas de la bahía de Coquimbo se fundan en la relación intrínseca entre las actividades de producción y la residencia. El habitar en directa relación con el oficio como comunidad ha construido tradiciones y un profundo sentido de arraigo que son fundamentales en la identidad de estas comunidades. El habitar junto al mar, la herencia del oficio y el crecimiento poblacional han ido moldeando los espacios de estos barrios. En la caleta de Peñuelas es muy evidente un modo de habitar asociado a la permanencia y apropiación de un espacio común. Este espacio, cargado de significados, es el lugar de lo propio y lo compartido, surgiendo como una entidad ambigua entre lo público y lo privado. El espacio común es el lugar del oficio y de la convivencia.

Un segundo aspecto relevante es la tradición familiar de la ocupación espacial. Se observa que los habitantes de las caletas constituyen una comunidad que se organiza a modo de clanes 
familiares y conservan una economía de escala humana, en que los modos de producción están arraigados a estructuras familiares. Las familias participan de la actividad productiva, no sólo a nivel primario, sino también generando actividades secundarias y terciarias principalmente ligadas a la gastronomía. Esto fortalece las unidades habitacionales, convirtiéndolas en unidades económicas con una fuerte carga simbólica. El saber-hacer local está cargado de una gran significación simbólica y afectiva (Saavedra y Macías, 2012)

En tercer lugar, la estructura de ocupación del asentamiento asoma como un factor determinante en la valoración del espacio. La densidad alcanzada por la caleta de Peñuelas y su trama peatonal propicia el encuentro de sus habitantes, la exteriorización de sus actividades cotidianas y una mayor riqueza perceptual de su espacialidad. El barrio Los Pescadores de Peñuelas se percibe consolidado, con historia y tradición. En San Pedro la percepción del espacio revela una urbanización realizada con patrones externos al contexto de la caleta. El espacio público de San Pedro es menos valorado por sus habitantes, quienes relevan la playa como el lugar más importante, espacio separado estructuralmente de la trama urbana de la localidad.

No obstante el grado de fortaleza de la apropiación espacial, ambas caletas están expuestas a fuertes presiones inmobiliarias, dada su ubicación privilegiada en la primera línea del borde costero de la bahía, y que no cuentan con una normativa particular que las proteja. Al estar localizadas en un área de riesgo de inundación por tsunamis o maremotos (Servicio Hidrográfico y Oceanográfico de la Armada de Chile, 2015), la permanencia original del patrimonio construido e inmaterial se ve amenazada, no sólo por la disolución de sus dinámicas cotidianas de barrio, sino también por la destrucción de su entorno físico que podría propiciar procesos de gentrificación contemporánea, como los ya observados en procesos de reconstrucción originados por desastres naturales (Inzulza y López, 2014).

\section{Referencias}

Ampuero, G. (1978). Notas para el estudio de la Cultura Diaguita. Boletín del Museo Arqueológico de La Serena, 16, 111-124.

Castillo, G. (1989). Agricultores y pescadores del Norte Chico: el Complejo Las Ánimas (800 a 1200 d.C.). En J. Hidalgo, V. Schiappacasse, H. Niemeyer, C. Aldunate, e I. Solimano (Ed.), Culturas de Chile, Prehistoria (265-276). Santiago de Chile: Editorial Andrés Bello.

Canales, M. (2006). Metodologías de investigación social introducción a los oficios. Santiago de Chile: Lom Ediciones.

Casgrain, A. y Janoschka, M. (2013). Gentrificación y resistencia en las ciudades latinoamericanas: el ejemplo de Santiago de Chile. Andamios, 10(22), 19-44.

Cerda, P. (2013). Patrimonio cultural indígena: norte semiárido de Chile. La Serena: Editorial Universidad de La Serena.

Concha, M. (1871). Crónica de La Serena, desde su fundación hasta nuestros días, 1549-1870. Santiago: Editorial Universidad de Chile.

Diario El Día. (2013). Caleta San Pedro y las delicias del mar [en línea]. Recuperado de http://diarioeldia.cl/articulo/caleta-san-pedro-delicias-mar

Fierro Page, M. (2015). Primer ensayo urbanístico regional, modernidad en La Serena, 1946-1952. Revista de Urbanismo, 32, 32-53. https://doi.org/10.5354/0717-5051.2015.36556

González Videla, G. (1975). Memorias Tomo 2. Santiago de Chile: Editorial Gabriela Mistral. 
Inzulza-Contardo, J. (2012). "Latino Gentrification"?: Focusing on physical and socioeconomic patterns of change in Latin American inner cities. Urban Studies, 49(10), 2085-2107. https://doi.org/10.1177/0042098011423425

Inzulza-Contardo, J. \& López, N. (2014). Gentrificación de escala intermedia global en Latinoamérica: el caso de la reconstrucción de Managua, Nicaragua 1972-2014. Revista de Urbanismo, 31, 56-75. https://doi.org/10.5354/0717-5051.2014.33274

Kosamu, I. (2015). Conditions for sustainability of small-scale fisheries in developing countries. Fisheries Research, 161, 365-373. https://doi.org/10.1016/j.fishres.2014.09.002

Lees, L., Shin, H. B., López, E., \& Herzer, H. (April, 2012). Towards an emerging geography of gentrification in the global south. Trabajo presentado en el congreso CEPAL - FAU Universidad de Chile, Santiago, Chile.

López Morales, E. (2009). Loretta Lees, Tom Slater \& Elvin Wyly. Gentrification. Revista de Geografía Norte Grande, 44, 155-158. https://doi.org/10.4067/s0718-34022009000300010

McGoodwin, J. R. (2002). Comprender las culturas de las comunidades pesqueras: clave para la ordenación pesquera y la seguridad alimentaria. Documento Técnico de Pesca, 401. Roma: FAO.

Marcucci, D. (2014). Coastal resilience: New perspectives of spatial and productive development for the Chilean caletas exposed to tsunami risk. Procedia Economics and Finance, 18, 39-46.

Max-Neef, M. (1998). Desarrollo a escala humana. Conceptos, aplicaciones y algunas reflexiones. Barcelona: Editorial Icaria.

Pozueta, J., Lamíquiz, F., y Porto, M. (2009). La ciudad paseable. Madrid: CEDEX.

Saavedra, G. y Macías, A. (2012). Tradición e innovación en las comunidades de pesca artesanal del sur de Chile: hacia un enfoque reflexivo del desarrollo endógeno. Revista de Antropología I beroamericana, 7(1), 33-64. https://doi.org/10.11156/aibr.070103

Sabatini, F., Worlmald, G., Sierralta, C., y Peters, P. (2010). Segregación residencial en Santiago: Tendencias 1992-2002 y efectos vinculados con su escala geográfica. En F. Sabatini, R. Salcedo, G. Wormald, \& G. Cáceres (Eds.), Tendencias de la segregación en las principales ciudades chilenas: Análisis censal 1982-2002 (pp. 19-42). Santiago de Chile: Pontificia Universidad Católica de Chile/Instituto Nacional de Estadísticas.

Segeur, S. (2015). Nuevas urbanizaciones costeras, ¿gentrificación turística en la bahía de Coquimbo? Revista de Urbanismo, 32, 18-31. http://dx.doi.org/10.5354/0717-5051.2015.36528

Servicio Hidrográfico y Oceanográfico de la Armada de Chile, SHOA. (2015). Carta de inundación por tsunami de las ciudades de Coquimbo y La Serena, Chile. Recuperado de http://www.shoa.cl/servicios/citsu/pdf/CITSU_Coquimbo_La_Serena_2da_Ed._2015.pdf

Servicio Nacional de Pesca, Sernapesca. (2013). Caletas pesqueras de Chile. Recuperado de https: $/ /$ www.sernapesca. $\mathrm{cl} /$ index.php?option $=$ com_remository\&l temid $=246 \&$ func $=$ fileinfo\&id $=565$ $\underline{4}$

Veliz, G. (1995). Conurbación La Serena-Coquimbo. La Serena: Imprenta Editorial Rosales. 


\section{URBANISMO}

ISSN 0717-5051

Revista de Urbanismo №34 - Enero - Junio de 2016

http://revistaurbanismo.uchile.cl Departamento de Urbanismo - FAU - Universidad de Chile

Zúñiga, S., Ramírez, P., y Valdebenito, M. (2008). Situación socioeconómica de las áreas de manejo en la región de Coquimbo, Chile. Latin American Journal of Aquatic Research, 36(1), 63-81. https://doi.org/10.3856/vol36-issue1-fulltext-5

Zúñiga, S., Ramírez, P., y Valdebenito, M. (2010). Medición de los impactos socio-económicos de las áreas de manejo en las comunidades de pescadores del norte de Chile. Latin American Journal of Aquatic Research, 38(1), 15-26. https://doi.org/10.3856/vol38-issuel-fulltext-2 